\title{
0 que Serviço Social quer dizer
}

\author{
What does social work mean
}

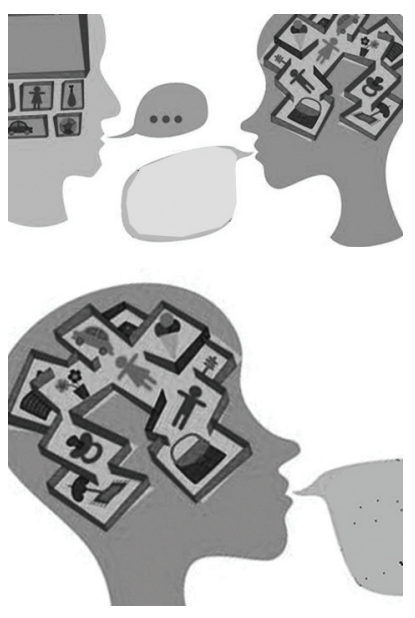

Vicente de Paula Faleiros*

Resumo: Este artigo trata da concepção/definição do Serviço Social em uma perspectiva histórica e teórica, levando em conta o contexto em que foi formulada e seus pressupostos. Tem como objetivo contrapor, de forma crítica, os enunciados discursivos sobre a profissão, sem nenhum propósito evolutivo ou exaustivo. O método foi de consulta bibliográfica a livros publicados de autores que tenham servido de referência e a definições de associações profissionais. O resultado da pesquisa mostrou uma diversidade de posições a partir do funcionalismo e do marxismo, da história e das práticas de serviço social.

Palavras-chave: Serviço Social. Definição de Serviço Social. Reconceituação.

\begin{abstract}
This article deals with the conceptions/definitions of social work from a theoretical and historical perspective, taking into account its context and presuppositions. The objective is a critical analysis of the discursive enunciations about the social work profession without any evolutional or exhaustive aim. The research method was a bibliography consultation of recognized authors, as well as of professional organizations. The results show that there is a diversity of positions from functionalism and marxism and from social movements and institutional practice.
\end{abstract}

Key-words: Social work. Social work definition. Reconceptualization.

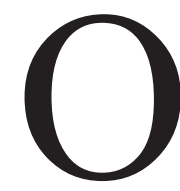

objetivo deste artigo é o de considerar os pressupostos que historicamente foram construídos para o estabelecimento de uma definição de Serviço Social. A elucidação desses pressupostos permite analisar não as definições isoladas, mas seu contexto e sua articulação com as de-

* Assistente social, Ph.D em Sociologia, pesquisador I-A do CNPq, professor da Universidade Católica de Brasília e colaborador da UnB — Brasília, Brasil. Coordenador do Cecria. E-mail: vicentefaleiros@terra. com.br. 
terminações sociais, econômicas, culturais e políticas. Não é pretensão deste estudo fazer um percurso histórico exaustivo do Serviço Social, mas da construção do discurso sobre o Serviço Social quanto a uma definição em vários contextos, a partir de sua formulação no início do século XX à primeira década do século XXI.

A construção do discurso sobre a definição do Serviço Social busca não só traduzir uma síntese enunciativa de elementos componentes do que se considera constituinte do Serviço Social, mas de articulá-lo com as determinações históricas e estruturais de sua construção e desconstrução.

Possenti e Souza-e-Silva (2008) consideram discursos constituintes aqueles que reconhecem a sua própria autoridade de definição, operando uma função na produção simbólica, tendo como referência uma visão científica ou profissional e que dão sentido a atos de reconhecimento e de legitimidade e também buscam uma coesão em torno dos mesmos.

A construção de uma definição sobre Serviço Social passa por disputas não só linguísticas, mas ideológicas e políticas, processadas no enfrentamento de projetos políticos e de produção de sentidos no cotidiano e de construção de estratégias e operações que sinalizam formas de ação dos profissionais.

Quando Silva (2004) fala de Mary Richmond, coloca como subtítulo de seu trabalho "Um olhar sobre os fundamentos do Serviço Social", ou seja, seu discurso fala de uma busca do que é fundamental para se entender o Serviço Social de casos. Richmond, segundo a autora, enfatiza a interação entre "personalidade e meio social", com o pressuposto do ajustamento de indivíduo a indivíduo e entre o homem e o meio social.

Esse discurso, considerado fundador, sinaliza como objeto da profissão o ajustamento social, o que é retomado reiteradamente nas definições de Serviço Social antes da Segunda Guerra Mundial. Fontoura (1959, p. 113) em um livro publicado em $1^{\text {a }}$ edição em 1949, afirma que o Serviço Social:

é o conjunto de técnicas que tem por objeto reajustar a personalidade humana, no sentido do seu pleno desenvolvimento físico, intelectual, moral e social, com o fim de tornar o homem mais feliz e proporcionar maior bem-estar à comunidade.

Enumera dezenove outras definições, inclusive do $1^{\circ}$ Congresso Brasileiro de Serviço Social de 1947, que ressalta sua origem cristã na solução de problemas sociais:

Serviço Social é a atividade destinada a estabelecer por processos científicos e técnicos o bem-estar da pessoa humana, individualmente ou em grupo, e constitui re- 
curso indispensável à solução cristã e verdadeira dos problemas sociais. (Fontoura 1959, p. 123)

Os problemas sociais são denominados de "deficiências sociais", que devem ser enfrentadas "por meios científicos", conforme definição adotada no $1^{\circ}$ Congresso Brasileiro de Direito Social de 1941: "Serviço Social é toda a ação dos poderes públicos, dos indivíduos ou das obras particulares tendo por objetivo prevenir, curar ou minorar por meio científicos as deficiências dos indivíduos e das coletividades" (Idem, p. 122).

Nas várias definições salientadas por Fontoura, o discurso constituinte se refere ao ajuste às condições sociais existentes e à correção de falhas ou males da sociedade ou à promoção do bem-estar.

A proposta de Fontoura e de outros autores é a de, por um lado, considerar uma evolução da caridade para a ação social e para o Serviço Social, incluindo neste uma ruptura com a filantropia e a piedade e incluindo uma visão técnica e científica da intervenção social.

A articulação entre a ação paliativa, curativa e preventiva fez parte da definição, tendo como valor a justiça social principalmente fundada nos parâmetros das encíclicas papais Rerum Novarum, de 1893 e Quadragesimo Anno, de 1933. A legitimidade do discurso está na construção de uma profissão cristã, que venha ao mesmo tempo promover o ajuste do indivíduo ao meio, a justiça social, o bem-estar com um procedimento técnico-científico.

Nessa visão da profissão predominam as questões da adaptação do sujeito a seu meio, a suas condições de trabalho (no capitalismo), aos valores dominantes, ou da melhora da satisfação consigo mesmo.

Essa concepção perpassa, de forma persistente na formação e na prática, quase todo o século XX. Em 1970, Bartlett (1979) reitera essa definição de bom funcionamento social, centrado na noção de "equilíbrio/interação" entre as pessoas e o meio, com orientação para as pessoas com problema. Ainda em 1982, reitera-se essa definição que reaparece no livro de Helen Northen, publicado no Brasil em 1984, que considera que:

Os objetivos para os quais a prática é dirigida reside no domínio das relações psicossociais ou vida social, e o profissional pode intervir em diversos sistemas-cliente, em qualquer nível de necessidade - fortalecimento, prevenção ou cura e pode usar modalidades de prática individual, de família ou grupo. (Northen, 1984, p. 43)

Ainda em 1995, Germain e Gitterman ressaltam que a função profissional é a de minimizar os estressores externos e potencializar os recursos internos e as pes- 
soas. Para os autores, o trabalhador social vai buscar as forças pessoais, familiares e ambientais. Na mediação das trocas entre a população e seu meio, os trabalhadores sociais encontram diariamente a falta de adaptação (fit) entre as necessidades da população e seu meio (p. 28). Ao mesmo tempo, para os autores, "os valores do serviço social constituem um conjunto de crenças que definem o que a profissão considera ser desejável e bom" (p. 29), o que implica a aceitação da sociedade dominante.

Toda essa proposta visa fortalecer o funcionamento psicossocial e maximizar as potencialidades das pessoas. A seu ver, mesmo a prevenção pressupõe a correção do mau funcionamento social. Esse discurso se ancora no funcionalismo dominante nos Estados Unidos e expresso nas teorias de Parsons (1902-79), que publica em 1937 o livro The structure of social action.

No livro Sociedades, Parsons $(1969$, p. 16) define a ação como "estruturas e processos, por meio dos quais os seres humanos formam intenções significativas e, com maior ou menor êxito, as executam em situações concretas". Volta à relação entre personalidade e meio, construindo-se na cultura as orientações da ação pela personalidade ou pelo organismo, que aprende e se adapta ao meio, sendo as intenções fundadas em padrões e valores que configuram a ordem social. Para ele, o processo de adaptação funciona por meio da integração ao sistema social.

O discurso da adaptação se torna mais complexo na articulação das funções da manutenção do padrão dominante pela integração e realização de objetivos, tanto pelos governos como pela economia e os sujeitos ou personalidades.

Assim, fundamentos ou pressupostos do Serviço Social, nas perspectivas do bom funcionamento social, são constitutivos do funcionalismo. Essa teoria, por sua vez, tem como pressuposto que o sistema capitalista vigente e dominante é constitutivo da sociedade, e seus valores de adaptação são sistêmicos ou normais.

A ruptura com essa visão normativa e com esse discurso pode ser apontada em 1942 quando Bertha Capen Reynolds (1942) coloca que o Serviço Social deve ser visto na estrutura social, assinalando que as concepções que consideram o Serviço Social como algo "bom" contra os males sociais são estáticas, pois "não levam em conta que o Serviço Social está dinamicamente unido com a sociedade contemporânea".

Deve ser visto na sua construção e sem as divisões de caso, grupo e comunidade ou de campos de ação e na discussão teórica. Também em relação com os movimentos sociais, ela considera uma visão amadora aquela que se restringe a problemas sociais ou à solução de problemas sociais, devendo-se articular o econômico, o social e o psicológico. Além de sair de uma prática autoritária, busca uma orientação de diagnóstico mais complexa e uma orientação que investigue as 
forças e potencialidades da própria população. Segundo ela, o assistente social deve integrar o conhecimento de si com o conhecimento do outro e, neste sentido, incorporando os conhecimentos da psicanálise e também considerando as demandas da população.

Reynolds rompe com a definição de uma helping profession para visão de uma protecting society em relação aos "desavantajados" (1942, p. 29). Critica a relação entre o que ajuda e o que é ajudado como relação de superioridade, levantando a questão de que a ajuda está estruturada pela sociedade, inclusive como a indústria do socorro e a ausência do Estado.

O pressuposto de que se deve qualificar a ajuda pela ciência ou pela técnica foi desconstruído por Reynolds como parte da estrutura capitalista e da indústria da ajuda, configurada como prática autoritária e ainda com uma orientação moralista e ilusória. A autora conclui pela necessidade de uma aprendizagem contínua do assistente social na relação com a população em dificuldade e com a população sem transtorno, também devendo-se articular a relação profissional com a de supervisor, de professor, bem como com a de executivo. Considera o Serviço Social uma arte complexa de articulação entre teoria e prática, em ruptura com a visão moralista. Salienta a necessidade do profissionalismo, de um corpo de conhecimentos e competências para o enfrentamento de situações novas de forma qualificada ("The tasks to be done for human welfare are no our toy", p. 336). Reynolds chama a atenção para a necessidade de um significado mais amplo de trabalho social como na URSS, na Inglaterra e na China, implicando "que em qualquer lugar que se trabalhe, deve-se fazê-lo para o todo".

Os pressupostos dos discursos de Reynolds, já por influência do marxismo, foram aprofundados e politizados pelo Radical Social Work dos anos 1970, como veremos.

Nos anos 1970 constrói-se também a perspectiva de análise do Serviço Social por influência das teorias de Foucault, passando a ser visto como uma forma de controle social (Dechamps, 1994). Verdès-Leroux (1986) considera que o controle social implicado no Serviço Social se coloca inicialmente como contenção das "classes perigosas", e no processo de industrialização, como forma de obtenção da pacificação de classes, com todo um "equipamento ideológico" para esse enfrentamento.

Karz (2004) pergunta se podemos e ou devemos definir o trabalho social e nos leva a refletir sobre ele como um lugar de pertencimento, de identidade, de execução de tarefas, enfim, como uma questão de disputa de espaços, poder, representações. Esse mesmo autor chama a atenção para o processo de reprodução ideológica que cabe ao Serviço Social na sociedade capitalista, como uma forma de controle social, de manutenção do status quo, inclusive articulando-se ao Esta- 
do capitalista. Essa função ideológica seria própria do trabalho social no seu processo de trabalho, pois sua matéria-prima seria as situações sociais significadas ideologicamente.

A questão da articulação do Serviço Social com a estrutura produtiva do capitalismo foi sendo cada vez mais aprofundada (Faleiros, 1972; Iamamoto, 1982; Netto, 1991; Raichelis, 2009). Nos anos 1970, Faleiros afirmava que "o Serviço Social se fundamenta na negação dos antagonismos do modo de produção capitalista" (1972, p. 12). Nessa linha o Radical Social Work (Brake e Bailey, 1975; Statham, 1978; Brake e Bailey, 1980) trouxe uma crítica não só ao capitalismo, mas também ao liberalismo, ao assinalar que a relação presente no Serviço Social implica uma desigualdade de poder e se articula à provisão de serviços sociais próprios das políticas dominantes.

No entanto, considera-se que a radicalidade na ação às vezes guarda uma relação com certo humanismo radical, mas levando em conta sua implicação ideológica no sentido de um compromisso com a classe trabalhadora. Esta foi a questão-chave do movimento de reconceituação na América Latina.

Conforme Faleiros (2005), a reconceituação, de linha marxiana, foi situada como o oposto ao Serviço Social tradicional com o questionamento crítico na busca de uma fundamentação teórica no marxismo, como fez a Escola de Serviço Social da Pontifícia Universidade Católica de Minas Gerais de 1972 a 1975 (Santos, 1982) e a Escuela de Trabajo Social de Valparaiso. Não se tratava, nesse caso, de repetir fórmulas do materialismo vulgar, mas de construir um projeto político da profissão. Buscava-se uma articulação, um compromisso, do Serviço Social com as reais necessidades da classe trabalhadora em suas relações históricas no contexto das sociedades capitalistas, em geral e em particular (Palma et al., 1972, p. 34).

Faz-se a crítica não somente ao capitalismo em geral, mas à sua forma dependente, concentradora e excludente na América Latina. A isso se agrega uma profunda crítica ao positivismo, ao indivíduo-problema e à mobilização de recursos. Ou seja, rompe-se com a lógica "pessoa/meio ambiente", própria do funcionalismo, como acima enunciado. Nesse sentido, toma-se como referência da ação a fundamentação dialética como ruptura com o linearismo do planejamento, então dominante no exercício profissional. Há um processo de dupla ruptura: com a ideologia da adaptação e seu tecnicismo e com a metodologia e a epistemologia positivistas.

A estrutura do planejamento que supõe diagnóstico, definição de objetivos, execução e avaliação serviu de parâmetro para a definição do Serviço Social no

1. Trata-se de um trabalho escrito em 1979. 
processo desenvolvimentista, com diferentes expressões, sejam voltadas para a integração no sistema dominante, seja para uma ação comprometida com a mudança, configurando-se o assistente social como agentes de mudança (Lima, 1974; Celats, 1986). Na perspectiva de planificação enfatiza-se, por um lado, o processo de participação e democracia, ou por outro, o metodologismo (Santos, 1982) próprio da racionalidade técnico-burocática (Faleiros, 2010).

No texto do Celats (1986) há ênfase para a participação. O Serviço Social é situado como uma profissão integrada no setor público ou privado, configurando um tipo de especialização do trabalho na sua divisão social e que contribui para o fortalecimento (calificación) dos usuários e das organizações populares, com uma "privilegiada dimensão política", definindo-se o profissional como "um ator político por excelência", atuante em espaços institucionais que são por sua vez contraditórios e ao mesmo tempo limitados.

Nesse texto (Celats, 1986, p. 33) afirma-se que o Serviço Social, no contexto institucional, não tem se identificado com a opção de assumir atitudes críticas diante das políticas sociais. Por sua vez, ao sistema capitalista não interessa uma definição muito clara do papel que o Serviço Social deve cumprir, configurando-se uma diversidade de ações tendentes tanto ao burocratismo como ao espontaneísmo e ao empirismo.

Já no início dos anos 1980 busca-se aprofundar a inserção do Serviço Social nas relações de trabalho institucionalizadas. Weisshaupt (1985) considera que objetivos profissionais e objetivos institucionais se articulam, pois o profissional é um agente subordinado na hierarquia, e seu objeto é estabelecido na relação de poder institucional, confirmando-se em sua pesquisa que é dominante a integração da população aos canais institucionais.

Essa vertente da análise institucional (Faleiros, 2007; Martin e Royer, 1987; Sousa, 1982; Weisshaupt, 1985; Serra, 2000; Bisneto, 2009) considera não só as relações de poder, como os processos de trabalho, a condição de contratos na lógica capitalista, mas diversificando-se sua análise conforme o tipo de organização onde se inscreve, por exemplo: organizações estatais, empresariais, não governamentais, de trabalhadores e mesmo autônomas (Cefess/Abepss, 2009). Essa diversidade ou heterogeneidade de ações advém da própria diversidade de inserção do Serviço Social.

É nessa diversidade e no confronto teórico e histórico de sua formação e formulação que se coloca hoje o desafio de se encontrar uma definição que possa agregar propostas de ação, valores e métodos. O propósito do Serviço Social, segundo a Associação de Assistentes Sociais Norte-Americanos (NASW, 2011) é a promoção do direito e da autodeterminação, com uma atitude de empatia para com 
o sujeito, mas levando em conta a cultura, as linguagens, as classes, as diversidades étnicas, habilidades, orientações religiosas, sexuais e diferentes expressões dos indivíduos. Afirma ainda que os assistentes sociais devem considerar "a pessoa no meio ambiente" (person-in-environment) com níveis macro e micro, com habilidades para influenciar mudanças políticas e desenvolvimento nos níveis local, estadual e federal, considerando os sistemas de cuidado, além de promover a pesquisa. Diferentemente da relação de pessoa e ambiente, a definição considera a pessoa no seu contexto.

O exercício da profissão, presente na definição da Federação Internacional de Trabalhadores Sociais (Fits, 2011), implica considerar a complexidade da ação, e não apenas a diversidade da intervenção, articulando-se a mudança com a resolução de problemas e a participação na busca dos direitos humanos e da justiça social:

O exercício da profissão de assistente social ou trabalhador social promove a mudança social, a resolução de problemas no contexto das relações humanas e a capacidade e empenhamento das pessoas na melhoria do "bem-estar". Aplicando teorias de comportamento humano e dos sistemas sociais, o trabalho social focaliza a sua intervenção no relacionamento das pessoas com o meio que as rodeia. Os princípios de direitos humanos e justiça social são elementos fundamentais para o trabalho social.

Nessa perspectiva, o Serviço Social pressupõe os princípios dos direitos humanos e da justiça social, o que está presente na consideração do Serviço Social progressista dos Estados Unidos e da Inglaterra. Figueira-McDonough (2007) afirma que além dos princípios liberais da liberdade e da igualdade, o Serviço Social deve articular a autonomia individual com a promoção da justiça social, na perspectiva dos direitos à liberdade e à igualdade. Assinala, no entanto, que na prática trabalha mais no sentido de promoção da autonomia que da justiça social e da participação democrática. Mas assinala que a busca da justiça é central para a profissão, sendo o que a distingue das outras. Isto implica análise das contradições da democracia liberal, das instituições e da identificação de políticas e do envolvimento profissional com as políticas de promoção da justiça social.

Em pesquisa realizada com assistentes sociais portugueses, Amaro (2009) constata que os valores de justiça dão identidade à profissão, mas constata também que falar de transformação, empowerment, justiça e respeito implica uma concretização na prática, embora a maioria dos profissionais considere que a mudança é uma característica emblemática da intervenção em Serviço Social. Essa mudança assume diferentes enfoques, como mudar a oportunidade, a situação, a mentalidade e a sociedade. 
Na realidade, o exercício do Serviço Social não se tensiona apenas entre propostas diferentes por parte dos profissionais, mas entre propostas societárias de mudanças. Nesse sentido, os profissionais brasileiros mobilizados pelas suas organizações profissionais (CFESS-Cress-Abepss) construíram uma proposta ético-política com compromisso democrático, da cidadania, de participação política e de crítica ao capitalismo e ao neoliberalismo "na luta pela construção de um novo projeto societário que tem como princípios fundamentais a liberdade e a justiça social" (CFESS-Cress, 1996). Essa perspectiva está presente no Código de Ética Profissional e vem sendo reafirmada nas manifestações políticas dos profissionais, o que se pode constatar nos sites do CFESS e dos Cress.

O CFESS (2011) propôs uma definição de Serviço Social no Congresso de Bem-Estar Social de Hong Kong de 2010 assim formulada:

$\mathrm{O}$ (A) trabalhador(a) social atua no âmbito das relações sociais, junto a indivíduos, grupos, famílias, comunidade e movimentos sociais, desenvolvendo ações que fortaleçam sua autonomia, participação e exercício de cidadania, com vistas à mudança nas suas condições de vida. Os princípios de defesa dos direitos humanos e justiça social são elementos fundamentais para o trabalho social, com vistas à superação da desigualdade social e de situações de violência, opressão, pobreza, fome e desemprego.

Essa definição considera o propósito de fortalecimento da autonomia, da cidadania da participação e de mudanças nas condições de vida. Esta perspectiva remete às relações de poder e correlações de forças formuladas por Faleiros (1997), segundo a qual o processo de intervenção profissional implica os pressupostos de deciframento analítico da estrutura, da conjuntura e da situação, numa perspectiva relacional e de articulação da participação do sujeito e atuação em redes e vínculos que permitam mediações gerais e particulares de assegurar direitos e que se transformem em estratégias de ação.

\section{Considerações Finais}

A redefinição do Serviço Social se articula a um processo histórico de crítica e autocrítica construído na interlocução da profissão com os movimentos sociais e lutas para mudar as condições particulares de vida das classes trabalhadoras e das condições gerais de reprodução da força de trabalho e do modo de produção capitalista.

Mesmo o fato de o Serviço Social emergir como profissão no contexto do capitalismo industrial no final do século XIX e início do XX não impediu que in- 
corporasse valores e ações próprios da filantropia religiosa, não deixando de ser um anacronismo. Anacronismo que se enraizava na ideologia religiosa das massas e no interesse de legitimar a ordem dominante pela "bondade".

No entanto, já na época de sua fundação emergiram as polêmicas sobre Serviço Social. Por exemplo, Jane Adams, contemporânea de Mary Richmond, defendia princípios feministas, de democratização, de respeito à diversidade cultural e de paz. Tanto assim que foi contemplada com o Prêmio Nobel da Paz (Travi, 2009). Como vimos acima, Bertha Reynolds já se inspirou no marxismo para uma crítica à visão adaptativa do Serviço Social em 1942.

No processo de acumulação capitalista, os exercícios profissionais foram se construindo articulados a uma expressão de controle dos segmentos dominados, de legitimação ideológica da ordem, de fragmentação de problemas, de individualização das demandas sociais, de integração aos objetivos institucionais. No entanto, numa perspectiva de politização desses exercícios, de pressão das organizações e movimentos sociais e de crítica à relação entre Serviço Social e capitalismo, vários grupos de profissionais, tanto na Europa, como nos Estados Unidos e na América Latina, produziram uma análise de seu contexto e de suas funções, ao mesmo tempo que se mobilizaram para uma perspectiva de mudança, de defesa de direitos, de participação e de articulação das demandas cotidianas diversificadas a projetos societários de transformação das relações de dominação e de exploração na busca de afirmação dos direitos humanos, da justiça social, da equidade, com respeito à diversidade social, cultural e de orientação sexual, religiosa ou política.

O gráfico a seguir assinala essas dimensões, as quais foram sendo historicamente construídas de forma não só contraditória, mas também polêmica.

Em primeiro lugar, é preciso salientar que o conceito de "meio" (environment) é profundamente criticado na visão marxista, pela consideração da estrutura capitalista e da produção/reprodução das desigualdades onde se insere o Serviço Social. A estrutura socioeconômica se articula à dimensão política do Estado, da cidadania e das políticas, mas são ligadas, na democracia, a direitos humanos e direitos reconhecidos (ver linhas laterais do triângulo), por um lado, e à participação, que envolve organização, mobilização, ação política. O Serviço Social se articula a uma visão política da sociedade e aos valores de justiça e equidade no enfrentamento da desigualdade.

No centro do triângulo observamos que as demandas sociais hoje são analisadas no contexto da estruturação sociopolítica e econômica, do saber profissional e das significações e expressões dos sujeitos em relação com sua diversidade, suas trajetórias, seus sofrimentos, exigindo do profissional que não só as tome em consideração, mas as articule com os direitos e procedimentos/instrumentos, bem como 
com as dimensões singulares e particulares das relações, percepções e condições da situação em relação às determinações mais gerais e em seu significado geral. Trata-se, assim, de um processo complexo de mediações políticas numa estrutura marcada pela exploração e pela dominação do ser humano e pela desigualdade no contexto capitalista e num Estado neoliberal. Desta forma, há que se considerar o gráfico a seguir de forma contraditória e conflituosa, como é o próprio Serviço Social na sua compreensão dialética. Nessas mediações estão implicadas as relações de poder e processos de trabalho nas instituições, onde se exige o deciframento crítico pela relação estrutura/conjuntura/situação e pela relação teoria/prática/ valores/movimentos profissionais e sociais/sujeitos em relação.

\section{Gráfico I}

Dimensões implicadas historicamente na redefinição do Serviço Social

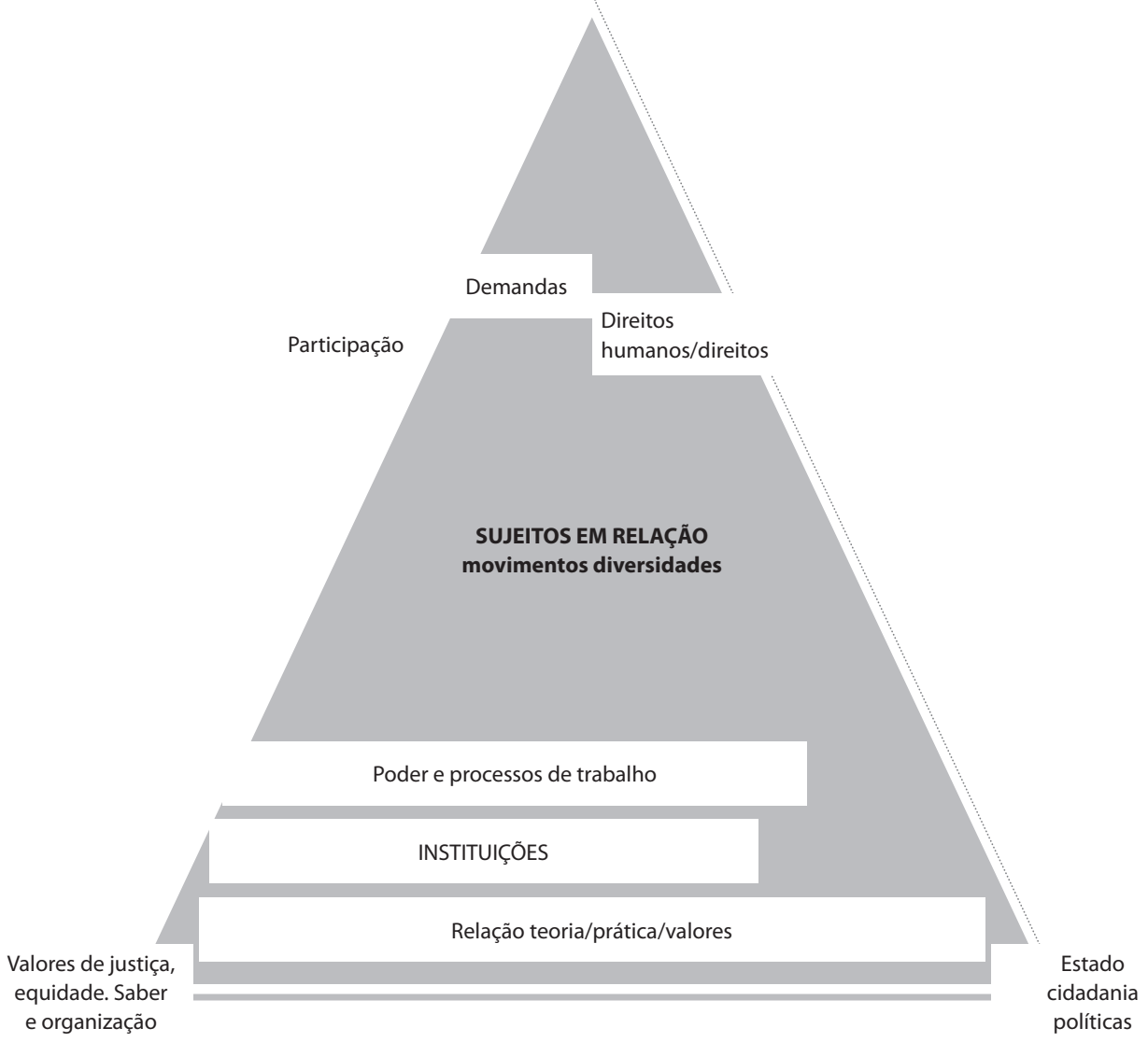


Recebido em 21/8/2011 - Aprovado em 5/9/2011

\section{Referências bibliográficas}

AMARO, Maria Inês Martinho Antunes. Urgências e emergências do Serviço Social contemporâneo: contributos para a discussão dos fundamentos da profissão. 2009. Tese (Doutorado) — sob a orientação do prof. Vicente de Paula Faleiros. Faculdade de Ciências Humanas, Universidade Católica Portuguesa, Lisboa.

ANDER-EGG, Ezequiel. Metodología del trabajo social. Barcelona: El Ateneo, 1982.

BARTLETT, Harriett. A base do Serviço Social. São Paulo: Pioneira Editora, 1979.

BISNETO, José Augusto. Serviço Social e saúde mental: uma análise institucional da prática. 2. ed. São Paulo: Cortez, 2009.

BRAKE, Mike; BAILEY, Roy (Org.). Radical social work. Nova York: Pantheon Books, 1975.

. Radical social work and practice. Londres: Edward Arnold, 1980.

CASTRO, Manuel Manrique. História do Serviço Social na América Latina. Tradução de José Paulo Netto e Balkys Villa Lobos. São Paulo: Cortez, 2000.

CBCISS - Documento de Sumaré. Debates Sociais - Suplemento n. 8. Rio de Janeiro: CBCISS, 1988.

CELATS. La práctica profesional del trabajador social. Lima: Hvmanitas, 1986.

CFESS. Proposta do CFESS para definição de Serviço Social. Disponível em: <www.cfess. org.br> Acesso em: 19 ago. 2011.

CFESS/ABEPSS. Serviço social: direitos sociais e competências profissionais. Brasília: CFESS/ABEPSS, 2009.

CFESS-CRESS. Serviço Social a caminho do século XXI: o protagonismo ético-político do conjunto CFESS-CRESS. Serviço Social \& Sociedade, São Paulo, n. 50, p. 172-190, abr. 1996.

CHOPOART, Jean-Noël. Les mutations du travail social. Paris: Dunod, 2000.

DECHAMPS, Ivan. Le travail social écartelé: pour un chemin praticable entre l'aide et le contrôle. Bruxelas: Editions Vie Ouviére, 1994.

FALEIROS, V. P. Estratégias em Serviço Social. 10. ed. São Paulo: Cortez, 2011.

. Saber profissional e poder institucional. 7. ed. São Paulo: Cortez, 2007. 
FALEIROS, V. P. A crise do planejamento. Serviço Social \& Saúde, Campinas, v. 9, p. 1-25, 2010.

Reconceituação do Serviço Social no Brasil: uma questão em movimento. Serviço Social \& Sociedade, São Paulo. v. 26, n. 84, p. 21-36, nov. 2005.

Trabajo social: ideología e método. Buenos Aires: Ecro, 1972.

FIGUEIRA-McDONOUGH, Josefina. The Welfare State and SOCIAL WORK: pursuing social justice. Londres: Sage, 2007.

FITS. Definição de Serviço Social. Disponível em: <http://www.ifsw.org/p38000377.html> Acesso em: 19 ago. 2011

FONTOURA, Amaral. Introdução ao Serviço Social. Rio de Janeiro: Gráfica Editora Aurora, 1959.

GERMAIN, Carel B.; GITTERMAN, Alez. The life model of social work practice. Nova York: Columbia University Press, 1995.

GRANEMANN, Sara. Processos de trabalho e Serviço Social. In: Capacitação em Serviço Social. Reprodução social, trabalho e Serviço Social. Brasília: CFESS/Abepss/Cead, 1999, v. 2.

IAMAMOTO, Marilda; CARVALHO, Raul de. Relações sociais e Serviço Social no Brasil. São Paulo: Cortez, 1982.

KARZ, Saül. Pourquoi le travail social. Définitions, figures, clinique. Paris: Dunod, 2004. LIMA, Boris A. Contribución a la metodología del trabajo social. Caracas: Universidade Central da Venezuela, 1974.

MARTIN, D.; ROYER, P. (Org.). L'intervention institutionnelle en travail social. Paris: L'Harmattan, 1987.

NASW. Social work practice in health care settings. 2005. Disponível em: <http://www. socialworkers.org/practice/standards/NASWHealthCareStandards.pdf $>$. Acesso em: 19 ago. 2011.

NETTO, José Paulo. Ditadura e Serviço Social. São Paulo: Cortez, 1991.

La crisis del proceso de reconceptualización del servicio social. In: ALAYÓN, Norberto et al. Desafio al servicio social. ¿Crisis de la reconceptualización? Buenos Aires: Humanitas, 1975.

NORTHEN, Helen. Serviço social clínico. Um modelo de prática. Rio de Janeiro: Agir, 1984.

PALMA, Eloisa Pizarro de et al. Que es trabajo social. Valparaíso: Ediciones UCV, 1972. 
PARSONS, Talcott. Sociedades: perspectivas evolutivas e comparativas. São Paulo: Pioneira, 1969.

POSSENTI, Sirio; SOUZA-E-SILVA, Maria Cecília Pérez de (Org.). Cenas da enunciação. São Paulo: Parábola, 2008.

RAICHELIS, Raquel. O trabalho do assistente social na esfera estatal. In: CFESS/Abepss. Serviço Social: direitos sociais e competências profissionais. Brasília: CEFESS/Abepss, 2009. v. 1.

REYNOLDS, Bertha Capen. Learning and teaching in the pratice of social work. Nova York: Rinehart \& Company, 1942.

SANTOS, Leila Lima. Textos em Serviço Social. São Paulo: Cortez, 1982.

SERRA, Rose. M. S. Crise de materialidade no Serviço Social: repercussão no mercado profissional. São Paulo: Cortez, 2000.

SILVA, Ilda Lopes Rodrigues da. Mary Richmond: um olhar sobre os fundamentos do Serviço Social. Rio de Janeiro: CBCISS, 2004.

SILVA, M. Ozanira da Silva e (Coord.). O Serviço Social e o popular. São Paulo: Cortez, 1995.

SOUZA, Maria Luiza. Serviço Social e instituição: a questão da participação. São Paulo: Cortez, 1982.

STATHAM, Daphne. Radicals in social work. Londres: Routledge \& Kegan Paul, 1978.

TRAVI, B. (Org.). Reconstrucción biográfica de la trayectoria profesional, académica y política de las pioneras del Trabajo Social (EEUU, 1860-1935). Prog. de Investigación PITS-EPHyD. Dto. de Cs. Sociales. Universidad Nacional de Luján, Argentina. 2009. Reg. Prop. Intelectual, Expte: 799455. Dcción. Nacional del Derecho de Autor.

VASCONCELOS, Ana Maria de. A prática do Serviço Social. São Paulo: Cortez, 2002.

VERDÈS-LEROUX, Jeannine. Trabalhador social: práticas, hábitos, ethos, formas de intervenção. São Paulo: Cortez, 1986.

WEISSHAUPT, Jean Robert (Org.). As funções socioinstitucionais do Serviço Social. São Paulo: Cortez, 1985. 